\section{Commentary: Let's start again!}

\author{
Antonio Miceli, MD, PhD
}

Left ventricular aneurysm (LVA) is a late mechanical complication of myocardial infarction and is defined as an area of systolic dyskinesia with paradoxical bulging. ${ }^{1}$ The incidence of this complication is less than in the past $(10 \%-35 \%)$ and currently affects approximately $5 \%$ of all patients with transmural myocardial infarction. ${ }^{2}$ This is probably the result of aggressive postischemic treatments, including percutaneous coronary intervention, angiotensinconverting enzyme inhibitors, and other medical therapies for advanced heart failure. LVA is often associated with arrhythmia, poor ejection fraction, and heart failure, and if left untreated, it is associated with poor survival at 5 years. ${ }^{3}$ Several left ventricular reconstruction techniques have been developed with the aim of restoring the left ventricular volume and shape, and encouraging results have been reported. ${ }^{4}$ Nevertheless, the number of these procedures has dramatically decreased in the last decade. Many factors such as early percutaneous treatment, surgical complexity, and poor long-term outcomes may have contributed to this decline. Most important, the Surgical Treatment of Ischemic Heart Failure trial failed to show any improvement in survival or ventricular function of adding surgical valve replacement (SVR) to coronary artery grafting in patients with left ventricular ejection fraction less than $35 \%$ and dominant anterior asynergy, although SVR achieved greater left ventricular end-systolic volume index reduction $(19 \%$ vs $6 \%))^{5}$ A major criticism on this trial was the inadequate volume reduction, which left the patients in the 2 arms at the identical risk. In an insight of the Surgical Treatment of Ischemic Heart Failure trial, Michler and colleagues ${ }^{6}$ identified a $30 \%$ volume reduction threshold for better survival. In the current issue of the Journal, Stefanelli and colleagues ${ }^{7}$ add evidence on the

From the Minimally Invasive Cardiothoracic Department, Istituto Clinico Sant'Ambrogio, Milan, Italy.

Disclosures: The authors reported no conflicts of interest.

The Journal policy requires editors and reviewers to disclose conflicts of interest and to decline handling or reviewing manuscripts for which they may have a conflict of interest. The editors and reviewers of this article have no conflicts of interest.

Received for publication May 12, 2020; revisions received May 12, 2020; accepted for publication May 12, 2020; available ahead of print May 27, 2020.

Address for reprints: Antonio Miceli, MD, PhD, Minimally Invasive Cardiothoracic Department, Istituto Clinico Sant'Ambrogio, Via LG Faravelli 16, Milano, Italy (E-mail: antoniomiceli7@alice.it)

J Thorac Cardiovasc Surg 2022;163:1068-9

$0022-5223 / \$ 36.00$

Copyright (c) 2020 by The American Association for Thoracic Surgery

https://doi.org/10.1016/j.jtcvs.2020.05.047

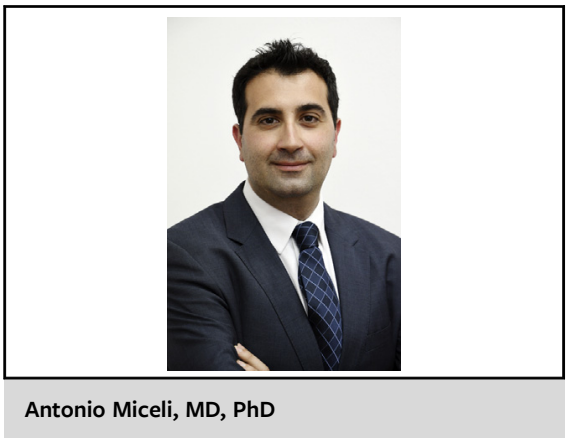

CENTRAL MESSAGE

In the next years, more patients will be referred for SVR as an indirect effect of COVID-19 for untreated myocardial infarction.

importance of performing a left ventricular volume reduction greater than $35 \%$ for survival benefits. Better longterm results were reached in those patients receiving the modified SVR technique compared with the Dor technique. According to the authors, the preservation of left ventricular diastolic function without the use of circumference pure strings and pericardial patch, and the restoration of the elliptic geometry represent the key of success of this procedure. Overall early mortality was $1.6 \%$, much lower than others with an overall survival of $68 \%$ at 5 years and $41 \%$ at 10 years. ${ }^{4}$ Nevertheless, the small sample size (represented by few patients at risk in Kaplan-Meier curve) and the inclusion of mitral valve treatment (potential impact on survival) represent major limits. In addition, this is a single surgeon experience, which may not be reproducible in other hands. Despite these limits, the authors present excellent timing in publishing this article. In my opinion, more SVR procedures will be performed in the next years. Data collected during the coronavirus disease 2019 (COVID19) pandemic have shown an important reduction rate of hospital admission for acute coronary syndrome, especially after lockdown. ${ }^{8,9}$ It is likely that patients avoid cardiovascular evaluation out of the fear of contracting COVID-19 in hospitals. As a consequence, LVA, ischemic mitral regurgitation, and heart failure will surge in the next years. The authors have demonstrated that LVA is safe and associated with early and long-term outcomes. Although the incidence of LVA has decreased over the time, in the next years more patients will be referred for SVR as an indirect effect of 
COVID-19 for untreated myocardial infarction. We have to prepare. Let's start again!

\section{References}

1. Davies RR, Coady MA. Mechanical complications of myocardial infarction. In: Yuh DD, Vricella LA, Baumgartner WA, eds. Manual of Cardiothoracic Surgery. New York: McGraw Hill; 2007:448-558.

2. Napodano M, Tarantini G, Ramondo A, Cacciavillani L, Corbetti F, Marra MP, et al. Myocardial abnormalities underlying persistent ST-segment elevation after anterior myocardial infarction. J Cardiovasc Med (Hagerstown). 2009;10:44-50.

3. Castelvecchio S, Garatti A, Gagliardotto P, Menicanti L. Surgical ventricular reconstruction for ischaemic heart failure: state of the art. Eur Heart J. 2016;18(Suppl E):E8-14.

4. Ruzza A, Czer LSC, Arabia F, Vespignani R, Esmailian F, Cheng W, et al. Left ventricular reconstruction for post infarction left ventricular aneurysm. Review of surgical techniques. Tex Heart Inst J. 2017;44:326-35.
5. Jones RH, Velasquez EJ, Micheler RE, Sopko G, Oh JK, O'Connor CM, et al. Coronary bypass surgery with or without surgical ventricular reconstruction. $N$ Engl J Med. 2009;360:1705-17.

6. Micheler RE, Rouleau JL, Al-Khalidi HR, Bonow RO, Pellikka PA, Pohost GM et al. Insights from the STICH trial: change in left ventricular size after coronary artery bypass grafting with and without surgical ventricular reconstruction. $J$ Thorac Cardiovasc Surg. 2013;146:1139-45.

7. Stefanelli G, Bellisario A, Meli M, Chiurla E, Barbieri A, Welter L. Outcomes af ter surgical ventricular restoration for ischemic cardiomyopathy. J Thorac Cardiovasc Surg. 2022;163:1058-67.

8. De Filippo O, D’Ascenzo F, Angelini F, Bocchino PP, Conrotto F, Saglietto A et al. Reduce rate of hospital admission for ACS during COVID-19 outbreak in northern Italy. $N$ Engl J Med. 2020;383:88-9.

9. Garcia S, Albaghdadi MS, Meraj PM, Schmidt C, Garberich R, Jaffer FA, et al. Reduction in ST-segment elevation cardiac catheterization laboratory activations in the United States during COVID-19 pandemic. J Am Coll Cardiol. 2020;75: 2871-2.
See Article page 1058.

\section{Commentary: Keys to surgical success: "Thinking outside the operating room?'”}

Ulrich Schneider, MD, and Torsten Doenst, $\mathrm{MD}, \mathrm{PhD}$

\section{WHAT DOES IT TAKE TO GENERATE} EXCELLENT RESULTS IN CARDIAC SURGERY?

Stefanelli and colleagues ${ }^{1}$ present outstanding results in this issue of the Journal for a controversial surgical technique, surgical ventricular restoration (SVR). How is that possible? The manuscript may appear as a perfect example to illustrate that cardiac surgery requires more than manual dexterity, it requires thinking, in and outside, the operating room $(\mathrm{OR})$.

Cardiac surgery has developed a plethora of reproducible surgical procedures with at times tremendous symptomatic as well as prognostic relevance. Nevertheless, some

\footnotetext{
From the Department of Cardiothoracic Surgery, Jena University Hospital, Friedrich Schiller University of Jena, Jena, Germany.

Disclosures: The authors reported no conflicts of interest.

The Journal policy requires editors and reviewers to disclose conflicts of interest and to decline handling or reviewing manuscripts for which they may have a conflict of interest. The editors and reviewers of this article have no conflicts of interest.

Received for publication May 6, 2020; revisions received May 6, 2020; accepted for publication May 11, 2020; available ahead of print May 25, 2020.

Address for reprints: Torsten Doenst, MD, PhD, Department of Cardiothoracic Surgery, Jena University Hospital Am Klinikum 1, D-07747 Jena, Germany (E-mail: doenst@med.uni-jena.de).

J Thorac Cardiovasc Surg 2022;163:1069-70

$0022-5223 / \$ 36.00$

Copyright (C) 2020 by The American Association for Thoracic Surgery

https://doi.org/10.1016/j.jtcvs.2020.05.036
}

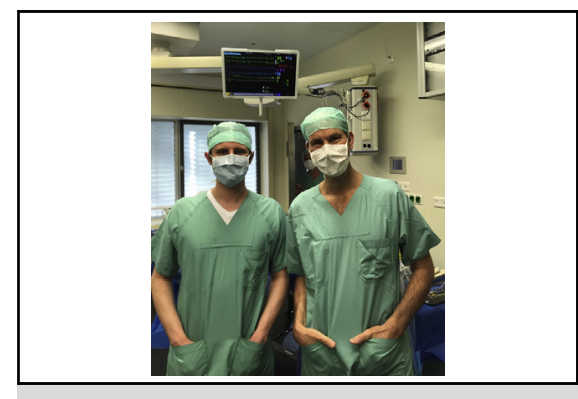

Ulrich Schneider, MD, and Torsten Doenst, MD, PhD

$$
\begin{aligned}
& \text { CENTRAL MESSAGE } \\
& \text { Success in cardiac surgery today } \\
& \text { requires more than gifted hands } \\
& \text { in the operating room. It is an } \\
& \text { interplay of many details in and } \\
& \text { outside of the operating room. }
\end{aligned}
$$

strategies remain a matter of debate, such as SVR. The Surgical Treatment for Ischemic Heart Failure (STICH) trial ${ }^{2}$ demonstrated improved survival of coronary artery bypass grafting in ischemic cardiomyopathy compared with medical therapy whereas adding SVR to coronary artery bypass grafting led to no further improvement. ${ }^{3}$ Consequently, SVR almost disappeared from the ORs worldwide. Nonetheless, with a cardiac survival probability of only $50 \%$ to $60 \%$ at 10 years, prognosis remains dismal regardless of the specific treatment. ${ }^{2}$

In contrast, Stefanelli and colleagues ${ }^{1}$ achieved an impressive $1.6 \% 30$-day-mortality and cardiac survival of approximately $70 \%$ at 10 years (up to $90 \%$ for ejection 